\title{
Phase Equilibrium and Dissociation Enthalpies for Cyclopentane + Methane Hydrates in $\mathrm{NaCl}$ Aqueous Solutions ${ }^{\dagger}$
}

\author{
Zhao-Yang Chen, ${ }^{\dagger}$ Qing-Ping Li, ${ }^{\ddagger}$ Zhong-Yuan Yan, ${ }^{\dagger}$ Ke-Feng Yan, ${ }^{\dagger}$ Zhi-Yong Zeng, ${ }^{\dagger}$ and Xiao-Sen $\mathrm{Li}^{*}{ }^{\dagger}$
}

Key Laboratory of Renewable Energy and Gas Hydrate, CAS, Guangzhou Institute of Energy Conversion, Chinese Academy of Sciences, Guangzhou 510640, China, and Technology Research Department, CNOOC Research Centre, Beijing 100027, China

\begin{abstract}
The phase equilibrium data of cyclopentane $(\mathrm{CP})+$ methane hydrates in brine water with $\mathrm{NaCl}$ mass fractions of $w=0,0.035,0.070$, and 0.100 were measured in the temperature range (284.4 to 301.3 ) $\mathrm{K}$ using a visual high-pressure phase equilibrium apparatus. The dissociation enthalpies of $\mathrm{CP}+$ methane hydrates in hot brine water were determined via the Clausius-Clapeyron equation based on these phase equilibrium data. The effect of help gas and salinity on the phase equilibrium of $\mathrm{CP}$ hydrate and $\mathrm{CP}+$ methane hydrates was studied, respectively. Liquid CP forms hydrates with small-molecule help gas at a temperature region much higher than the quadruple point of pure $\mathrm{CP}$ hydrate. Methane partially occupied the small cages of structure II hydrate, which accelerates the nucleation and growth of $\mathrm{CP}+$ methane hydrates and increases the stability of the hydrates. The phase equilibrium pressure of $\mathrm{CP}+$ methane hydrates increases with the increase in temperature, and it increases linearly with the increase in $\mathrm{NaCl}$ concentration in solutions. The higher the temperature, the more remarkable effect the temperature and salinity has on the phase equilibrium pressure. The dissociation enthalpy decreases with the increase in temperature and the $\mathrm{NaCl}$ concentration.
\end{abstract}

\section{Introduction}

Gas hydrates (also known as clathrate hydrates) are solid, nonstoichiometric crystalline compounds formed from water and small gas molecules $(<0.9 \mathrm{~nm})$ at high pressures and low temperatures. A huge amount of natural gas hydrates (NGHs) occur naturally within or under permafrost regions and ocean sediments. The most recent estimates of the total amount of methane (STP) trapped in these hydrated gas deposits vary from $\left(0.2 \cdot 10^{15}\right.$ to $\left.12 \cdot 10^{16}\right) \mathrm{m}^{3}{ }^{1}$ Accordingly, NGHs are considered to be a potential energy resource in the 21 st century. ${ }^{2}$

The methods that have been put forward to destabilize NGHs for gas production include: thermal stimulation, ${ }^{3}$ depressurization, ${ }^{4}$ chemical inhibitor injection, ${ }^{5}$ and replacement of methane by $\mathrm{CO}_{2}$ hydrate. ${ }^{6}$ The depressurization method is demonstrated to be highly energy efficient when the NGH deposits are in conjunction with a free-gas zone. However, it will not likely provide a steady, reliable gas production because the dissociation rate of NGHs is controlled by the rate of heat flux from the surrounding media or by the thermal conductivity of the surrounding rock matrix. Thermal stimulation is capable of producing substantial amounts of natural gas, especially when it is combined with the depressurization or chemical injection methods. ${ }^{7}$ However, thermal stimulation through injection of steam or hot water suffers from significant heat loss during transit of the steam or hot water from the ocean surface to the $\mathrm{NGH}$ region. The use of hot brine for dissociation of hydrates was thought be an attractive recovery scheme because it can reduce the dissociation temperature and dissociation enthalpy of NGHs, thus decreasing the requirements of sensible heat and hydrate dissociation energy, as well as heat losses. ${ }^{8}$

\footnotetext{
"Part of the "Sir John S. Rowlinson Festschrift".

* Corresponding author. Tel.: +862087058468. Fax: +862087057037.

E-mail: lixs@ms.giec.ac.cn.

Chinese Academy of Sciences.

$\div$ CNOOC Research Centre.
}

We developed a novel technique to prepare hot brine in situ seafloor for marine NGH exploitation based on hydrate technology. ${ }^{9}$ In this recovery scheme, a hydrate-forming agent is introduced into an apparatus installed in situ seafloor, in which the hydrate-forming agent forms solid hydrates with seawater spontaneously under submarine high-pressure conditions. The exothermic effect and desalination effect during the formation of hydrate raise the temperature and salinity of the residual seawater, respectively. The hot brine thus prepared is injected into the NGH deposits for NGH dissociation after the solid hydrates float up to the ocean surface by their own buoyancy. The hydrate-forming agent is recovered and recycled at the ocean surface when the solid hydrates float up and decompose into the hydrate-forming agent and water due to the decrease in pressure. The new NGH exploitation process avoids significant heat loss during transiting the heat carrying medium from the ocean surface to the NGH regions in conventional thermal stimulating methods. The hot brine preparation process is to some extent similar to the hydrate desalination process proposed by Max. ${ }^{10}$ However, the residual brine with relatively high temperature is needed in current technology, while the solid hydrate is needed in Max's desalination process. Thereby, the hydrate-forming agent and operating parameters are different. The preferred hydrate-forming agent must meet the following requirements: First, the hydrate-forming agent is cheap, nontoxic or low toxic, and insoluble with seawater, and the density of the solid hydrates is lower than that of brine to facilitate its recovery and recycling. Second, the hydrate formation temperature under submarine pressure should be higher than that of methane and as high as possible. Third, the hydrate formation enthalpy should be as high as possible.

Some intermediate/heavy hydrate-forming compounds, such as cyclopentane (CP), ${ }^{11}$ can form structure II or structure $\mathrm{H}$ hydrate at lower pressure and higher temperature conditions than methane by simultaneously use a heavy hydrate former with a 


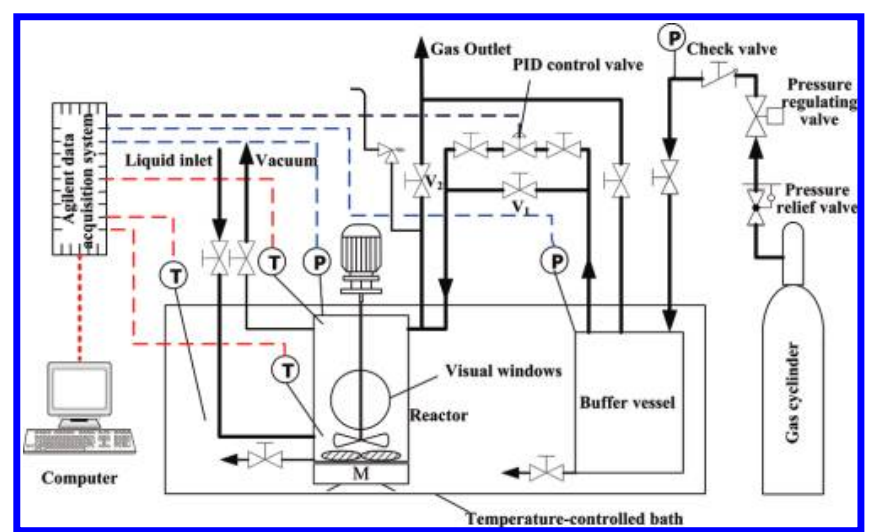

Figure 1. Schematic diagram of the experimental system. PID, proportionalintegral-derivative; $\mathrm{V}_{1}, \mathrm{~V}_{2}$, valves.

help gas as guest substances. ${ }^{12,13}$ These compounds may be an option for our hydrate-forming agents. The equilibrium pressures of $\mathrm{CP}+$ methane hydrate in pure water range from $(0.165$ to 7.312) $\mathrm{MPa}$ in the temperature range (282.15 to 301.90$) \mathrm{K}^{14}$ The pressure range is lower than the submarine pressure conditions (ca. (5 to 40) MPa) where common NGH occurs. Several other studies have reported the dissociation conditions of binary hydrates of $\mathrm{CP}$ with different help gases in pure water, such as $\mathrm{CH}_{4},{ }^{15,16} \mathrm{~N}_{2},{ }^{16} \mathrm{H}_{2},{ }^{17} \mathrm{CO}_{2},{ }^{17} \mathrm{H}_{2} \mathrm{~S},{ }^{15}$ krypton, ${ }^{18}$ and difluoromethane. ${ }^{19}$ Taylor et al. ${ }^{20}$ investigated the hydrate film growth versus time and subcoolings at the $\mathrm{CP} /$ water interface using video microscopy combined with gas consumption measurements. Sakemoto et al. ${ }^{21}$ observed CP hydrate crystal growth at the seawater and CP interface. Whitman et al. ${ }^{22}$ and Zhang et al. ${ }^{23}$ studied the nucleation mechanism of CP hydrate in the $\mathrm{CP} /$ water emulsion system using differential scanning calorimetry.

Despite the progress made in these studies, most of these studies are related to $\mathrm{CP}$ hydrate in pure water or additives containing solutions. There were no equilibrium data available for $\mathrm{CP}+$ methane hydrates in brine water. In this work, the phase equilibrium pressures of $\mathrm{CP}+$ methane hydrates were measured in the temperature range (284.4 to 301.3 ) $\mathrm{K}$ and in brine water containing the $\mathrm{NaCl}$ mass fraction of $w=0,0.035$, 0.070 , and 0.100 . The formation/dissociation enthalpies of $\mathrm{CP}$ + methane hydrates in brine water were determined based on the obtained phase equilibrium data of $\mathrm{CP}+$ methane hydrates in $\mathrm{NaCl}$ solutions.

\section{Experimental Section}

Apparatus. The schematic diagram of the experimental apparatus used in this work is shown in Figure 1. The major portion of the setup was a cylindrical reactor immersed in a temperature-controlled water bath containing approximately 50/ 50 mass percent water and ethylene glycol. The maximum working pressure of the reactor was $30 \mathrm{MPa}$. It was made of 316 stainless steel and had an internal volume of about 416 $\mathrm{mL}$. Two quartz glass visual windows were equipped at the front and back of the reactor and allowed visual observation of phase transition in the reactor. The reactor contents were agitated and mixed by a magnetic spin bar placed directly at the bottom of the reactor or by a magnetically driven three-paddle helical impeller mounted on the top of the reactor. A baffle arrangement was used in the reactor to prevent vortex formation and to enhance mixing of the contents. The temperature in the reactor was controlled by the temperature-controlled water bath with a temperature range of $(-15$ to 50$){ }^{\circ} \mathrm{C}$ and a temperature- controlling accuracy of $\pm 0.1 \mathrm{~K}$. Two Pt1000 thermoprobes (JM6081) with $\pm 0.05 \mathrm{~K}$ accuracy were used to measure the temperature at the top (gas phase) and the bottom (liquid phase) of the reactor, respectively. To minimize the perturbation of temperature and pressure in the reactor caused by methane charges, a buffer vessel (1.0 L, $30 \mathrm{MPa})$ immersed in the temperature-controlled water bath was used to precool and to measure the amount of the supplied gas. The pressure in the reactor was controlled by a proportional-integral-derivative controlled pressure regulated valve (Tescom ER3000) with a pressure-controlling accuracy of $\pm 0.02 \mathrm{MPa}$. All pressures in the experimental apparatus were measured using a Danfoss MBS3000 absolute pressure transducer, with a range of (0 to 400) bar and accuracy $\pm 0.02 \mathrm{MPa}$. Temperature and pressure data were collected every $6 \mathrm{~s}$ using an Agilent model 34970A recording system, which was controlled by the Agilent data acquisition software application BenchLink.

Materials and Preparation of Samples. The methane with the mole fraction of 0.999 was supplied by Guangdong South China Special Gases Technology Institute Ltd., China. CP with the mass fraction of 0.995 was supplied by Chengdu Best Reagent Co., Ltd., China. $\mathrm{NaCl}$ with the mass fraction of 0.995 was supplied by Guangzhou Second Chemical Reagent Factory, China. All aqueous solutions were prepared by deionized water which was prepared by an ultrapure water system (Nanjing Ultrapure Water Technology Co., Ltd., China) with a resistivity of $18.25 \mathrm{M} \Omega \cdot \mathrm{cm}$.

Procedure. The isothermal pressure search method was employed to determine the hydrate dissociation pressure at a given temperature and a given $\mathrm{NaCl}$ concentration in water. ${ }^{24}$ The experimental apparatus was washed and rinsed with deionized water, purged with methane three times, and evacuated with a vacuum pump before experimentation. Amounts of 210 $\mathrm{mL}$ of $\mathrm{NaCl}$ aqueous solution and $25 \mathrm{~mL}$ of $\mathrm{CP}$ were charged into the reactor under stirring. The buffer vessel was pressurized to the desired pressure with methane. After the temperature of the system was cooled to the predetermined value and remained stabilized by the water bath, the reactor was pressurized with the precooled methane in the buffer vessel to a pressure exceeding the estimated equilibrium pressure by about $1.0 \mathrm{MPa}$ to reduce the induce time. After the hydrate crystal was observed through the glass windows, the pressure was reduced gradually by discharging methane out of the reactor slowly until the hydrate crystals decomposed completely. Then the pressure of the reactor was raised slowly again with the precooled methane in the buffer vessel until a small quantity of hydrate crystal appeared again. When the charging pressure $\left(P_{\mathrm{f}}\right)$ of the reactor and the hydrate crystal remained stable for ( 2 to 3$) \mathrm{h}$, the pressure in the reactor was reduced slowly again to allow the hydrate to decompose. The discharging pressure $\left(P_{\mathrm{d}}\right)$ of the reactor was recorded at the moment the hydrate disappeared completely. The above pressure raising and reducing step (or hydrate formation and decomposition process) was repeated until $P_{\mathrm{f}}-P_{\mathrm{d}} \leq 0.05 \mathrm{MPa}$. At each repetition, the charging pressure $P_{\mathrm{f}}$ was controlled lower than the former repetition, and the discharging pressure $P_{\mathrm{d}}$ was controlled higher than the former repetition. The $P_{\mathrm{f}}$ of the last repetition was taken as the hydrate phase equilibrium pressure at the given temperature and the given $\mathrm{NaCl}$ concentration in water.

In these experiments, the test fluids were composed of four components (methane, $\mathrm{CP}, \mathrm{NaCl}$, and water) and four phases (vapor, liquid hydrocarbon, brine water, and hydrate). The concentration of $\mathrm{NaCl}$ in aqueous solution remains constant and is not an independent variable for each given experiment because 


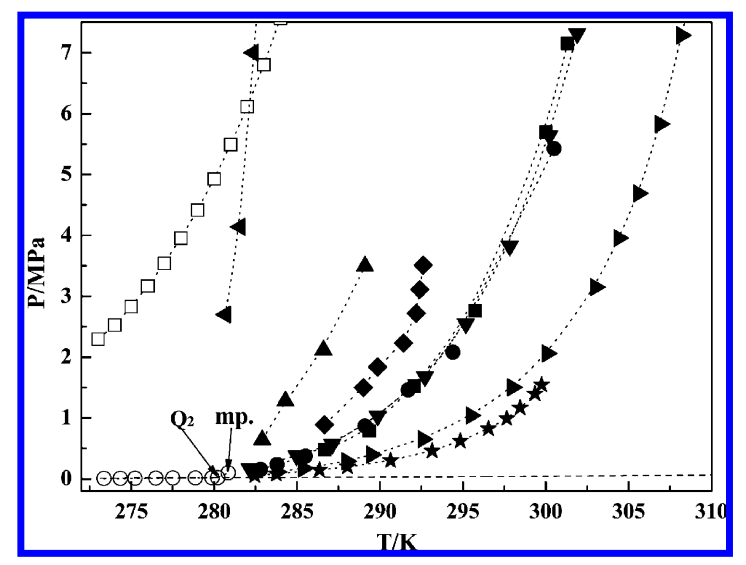

Figure 2. Effect of help gas on phase equilibrium conditions of cyclopentane hydrates in pure water. $\square, \mathrm{CH}_{4}+\mathrm{H}_{2} \mathrm{O}$, present work; $\mathbf{D}, \mathrm{CP}+\mathrm{CH}_{4}+$ $\mathrm{H}_{2} \mathrm{O}$, present work; $\mathrm{O}, \mathrm{CP}+\mathrm{H}_{2} \mathrm{O}$, Fan et al. ${ }^{11} \nabla, \mathrm{CP}+\mathrm{CH}_{4}+\mathrm{H}_{2} \mathrm{O}$, Sun et al. ${ }^{14} \bullet, \mathrm{CP}+\mathrm{CH}_{4}+\mathrm{H}_{2} \mathrm{O}, \boldsymbol{\Delta}, \mathrm{CP}+\mathrm{N}_{2}+\mathrm{H}_{2} \mathrm{O}$, Tohidi et al. ${ }^{16} \bullet, \mathrm{CP}$ $+\mathrm{CO}_{2}+\mathrm{H}_{2} \mathrm{O}$, solid triangle pointing left, $\mathrm{CP}+\mathrm{H}_{2}+\mathrm{H}_{2} \mathrm{O}$, Zhang et al. ${ }^{17}$ solid triangle pointing right, $\mathrm{CP}+\mathrm{Kr}+\mathrm{H}_{2} \mathrm{O}$, Takeya et al. ${ }^{18} \star, \mathrm{CP}$ $+\mathrm{CH}_{2} \mathrm{~F}_{2}+\mathrm{H}_{2} \mathrm{O}$, Imai et al.; ${ }^{19}$ - - -, vapor-liquid equilibrium line; $\mathrm{Q}_{2}$, quadruple point of pure $\mathrm{CP}$; $\mathrm{mp}$, melting point of $\mathrm{CP}$ hydrate.

the hydrate crystal is controlled very small, and it nearly does not affect the $\mathrm{NaCl}$ concentration in brine water when the system reaches the phase equilibrium pressure. Thus, according to the Gibbs phase rule, there is only one degree of freedom for the above system at a given $\mathrm{NaCl}$ aqueous solution.

\section{Results and Discussion}

Effect of Help Gas on Hydrate Equilibrium Conditions of Cyclopentane. The hydrate dissociation conditions of CP and $\mathrm{CP}+$ help gas in pure water are shown in Figure 2. Liquid $\mathrm{CP}$ form hydrates at a temperature range much higher than the quadruple point of $\mathrm{CP}$, when a help gas, such as $\mathrm{CH}_{4}, \mathrm{CO}_{2}, \mathrm{~N}_{2}$, $\mathrm{H}_{2}, \mathrm{Kr}$, or $\mathrm{CH}_{2} \mathrm{~F}_{2}$, is employed. Cyclopentane can form structure II hydrates without any help gas to fill its small cavities. The pressure of the three-phase equilibrium line of $\mathrm{CP}(\mathrm{V})$-water $\left(\mathrm{L}_{\mathrm{W}}\right)$-hydrate $(\mathrm{H})$ is lower than atmospheric pressure, and the quadruple point occurred at a temperature of $280.22 \mathrm{~K}$ and a pressure of $19.8 \mathrm{kPa}^{11}$ The pressures of the three-phase equilibrium line of $\mathrm{CP}\left(\mathrm{L}_{\mathrm{HC}}\right)$ - water $\left(\mathrm{L}_{\mathrm{W}}\right)$-hydrate $(\mathrm{H})$ increase vertically when the temperature is higher than the quadruple point. So there is very little study on hydrate phase equilibrium conditions of pure $\mathrm{CP}+$ water at a temperature higher than the quadruple point. At the same time, in a homogeneous nucleation system, CP hydrate could not form until ice occurs and acts as a nucleating agent at a temperature of $-38^{\circ} \mathrm{C} .{ }^{22,23}$ Although the supercooling required for heterogeneous nucleation is smaller than that for homogeneous nucleation, $\mathrm{CP}$ hydrate is still difficult to form. We had even stirred the $\mathrm{CP}+$ water system at $2{ }^{\circ} \mathrm{C}$ for 5 days, and there was no $\mathrm{CP}$ hydrate generation, though the melting point of $\mathrm{CP}$ hydrate is about $7.7^{\circ} \mathrm{C}$ at an atmospheric pressure. ${ }^{23}$ According to the Chen-Guo model, ${ }^{25}$ cyclopentane forms labile clusters with a number of water molecules surrounding the $\mathrm{CP}$ molecule when $\mathrm{CP}$ is mixed with water. These clusters, which are the rudiment of a large cage of structure II hydrate, will join together and form basic hydrate when the concentration of these $\mathrm{CP}$-water clusters in water reaches a certain value. The basic hydrate is difficult to grow large enough to create a hydrate nucleus without help gas. However, in the presence of small molecule help gas, these help gases will fill into the linked cavities (small cage of structure II hydrate) of $\mathrm{CP}$ basic hydrate, and this increases the stability of the basic hydrate. So the $\mathrm{CP}$ basic hydrate can easily grow
Table 1. Four-Phase Equilibrium $P, T$ Conditions of CP-Rich Liquid $+\mathrm{CH}_{4}$-Rich Vapor + Pure Water or $\mathrm{NaCl}$ Aqueous Solutions-Rich Liquid + Hydrate System and the Dissociation Enthalpy of CP + Methane Hydrates

\begin{tabular}{|c|c|c|c|c|}
\hline \multirow[b]{2}{*}{$w$} & $T$ & $P$ & \multirow[b]{2}{*}{$Z$} & \multirow{2}{*}{$\frac{\Delta_{\mathrm{diss}} H_{\mathrm{m}\left(\mathrm{CH}_{4}\right)}}{\left(\mathrm{kJ} \cdot \mathrm{mol}^{-1}\right)}$} \\
\hline & K & $\mathrm{MPa}$ & & \\
\hline \multirow[t]{6}{*}{0.000} & 286.67 & 0.480 & 0.990 & 130.25 \\
\hline & 289.35 & 0.790 & 0.985 & 129.52 \\
\hline & 292.26 & 1.525 & 0.972 & 127.84 \\
\hline & 295.75 & 2.760 & 0.953 & 125.32 \\
\hline & 300.02 & 5.694 & 0.914 & 120.22 \\
\hline & 301.31 & 7.151 & 0.899 & 118.49 \\
\hline \multirow[t]{9}{*}{0.035} & 284.50 & 0.622 & 0.987 & 122.46 \\
\hline & 286.71 & 0.825 & 0.984 & 122.01 \\
\hline & 289.24 & 1.350 & 0.974 & 120.86 \\
\hline & 291.95 & 2.250 & 0.959 & 118.99 \\
\hline & 295.77 & 4.269 & 0.929 & 115.27 \\
\hline & 297.73 & 5.906 & 0.908 & 112.68 \\
\hline & 299.06 & 7.400 & 0.892 & 110.68 \\
\hline & 301.31 & 10.513 & 0.869 & 107.73 \\
\hline & 303.28 & 15.094 & 0.857 & 106.34 \\
\hline \multirow[t]{9}{*}{0.070} & 284.40 & 0.788 & 0.984 & 114.70 \\
\hline & 286.57 & 1.183 & 0.977 & 113.85 \\
\hline & 289.14 & 1.775 & 0.966 & 112.66 \\
\hline & 292.01 & 2.700 & 0.952 & 110.92 \\
\hline & 295.67 & 4.956 & 0.919 & 107.13 \\
\hline & 297.94 & 7.113 & 0.894 & 104.19 \\
\hline & 299.33 & 8.800 & 0.878 & 102.39 \\
\hline & 301.31 & 11.888 & 0.861 & 100.33 \\
\hline & 303.28 & 17.806 & 0.850 & 99.06 \\
\hline \multirow[t]{9}{*}{0.100} & 284.40 & 1.100 & 0.978 & 107.71 \\
\hline & 286.57 & 1.619 & 0.968 & 106.67 \\
\hline & 289.14 & 2.219 & 0.958 & 105.57 \\
\hline & 292.01 & 3.344 & 0.940 & 103.58 \\
\hline & 295.67 & 5.788 & 0.907 & 99.95 \\
\hline & 297.94 & 8.313 & 0.881 & 97.01 \\
\hline & 299.33 & 10.481 & 0.865 & 95.25 \\
\hline & 300.71 & 14.261 & 0.852 & 93.86 \\
\hline & 301.31 & 16.344 & 0.848 & 93.44 \\
\hline
\end{tabular}

continuously and form macroscopic hydrate crystals at mild conditions when help gas presents.

The hydrate formation conditions of $\mathrm{CP}+$ methane hydrates in water measured in this work are very consistent with the data reported by Sun et al. ${ }^{14}$ and Tohidi et al. ${ }^{16}$ The phase equilibrium pressure of $\mathrm{CP}+$ methane hydrates in water increase with the increase in temperature. The higher the temperature is, the greater the phase equilibrium pressure increase. The pressures of $\mathrm{CP}\left(\mathrm{L}_{\mathrm{HC}}\right)$ - methane $(\mathrm{V})$ - water $\left(\mathrm{L}_{\mathrm{W}}\right)$-hydrates $(\mathrm{H})$ four-phase equilibrium are in the range $(0.48$ to 5.694$) \mathrm{MPa}$ when the temperatures are in the range (286.67 to 300.02$) \mathrm{K}$. Compared to methane hydrate, the dissociation temperature of $\mathrm{CP}+$ methane hydrate is about $20{ }^{\circ} \mathrm{C}$ higher than that of methane at the same pressure. Although the equilibrium temperature of $\mathrm{CP}+$ methane hydrates is lower than that of $\mathrm{CP}+\mathrm{Kr}$ and $\mathrm{CP}+\mathrm{CH}_{2} \mathrm{~F}_{2}$ hydrates at the same pressure, $\mathrm{CP}$ + methane is considered as a hydrate former in our hydratebased hot brine preparation because we can take advantage of local materials of seawater and methane recovered from NGHs. The main energy consumption required for the hot brine preparation comes from injecting CP from the ocean surface to the seafloor, as well as separating and recovering of cyclopentane.

Effect of Salinity on Hydrate Equilibrium Conditions of Cyclopentane + Methane. In this work, $\mathrm{NaCl}$ aqueous solutions were used as simulated brine water. The four-phase equilibrium data of $\mathrm{CP}\left(\mathrm{L}_{\mathrm{HC}}\right)$ - methane $(\mathrm{V})$ - brine water $\left(\mathrm{L}_{\mathrm{BW}}\right)$-hydrates (H) are listed in Table 1 . The equilibrium phase diagrams of $\mathrm{L}_{\mathrm{HC}}-\mathrm{V}-\mathrm{L}_{\mathrm{BW}}-\mathrm{H}$ are displayed in Figure 3. As can be seen from Table 1 and Figure 3a, the phase equilibrium pressures of $\mathrm{CP}$ + methane hydrates in brine water increase with the increase 

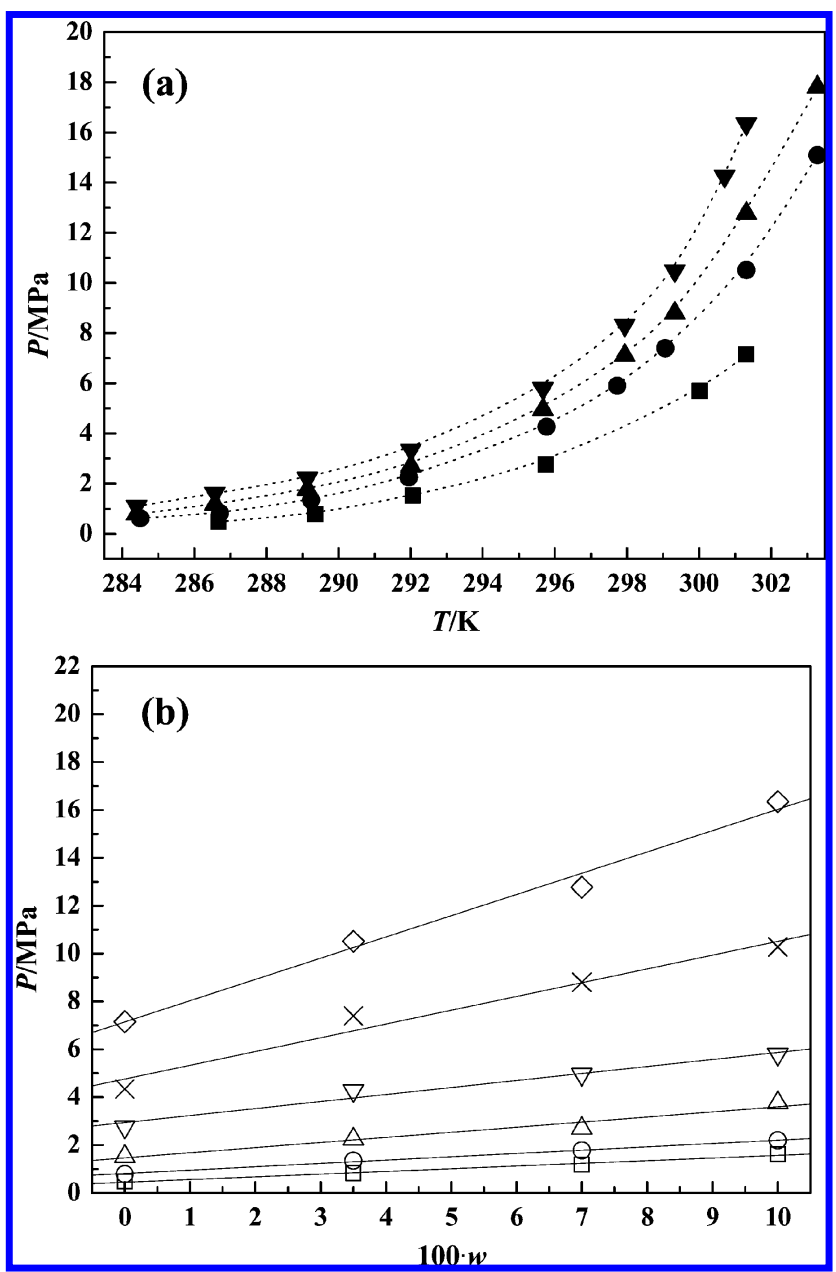

Figure 3. Effect of $\mathrm{NaCl}$ concentration on phase equilibrium conditions of $\mathrm{CP}+\mathrm{CH}_{4}$ hydrates. (a) $P-T$ phase plot; $\mathbf{\square}, w=0.000 ; \boldsymbol{\bullet}, w=0.035 ; \boldsymbol{\Delta}$, $w=0.070 ; \nabla, w=0.100$. (b) $P-100 \cdot w$ phase plot; $\square, T=(286.57$ to 286.71) $\mathrm{K}, k=0.1123, r=0.9957$; $\mathrm{O}, T=(289.14$ to 289.24$) \mathrm{K}, k=$ $0.1390, r=0.9986 ; \Delta, T=(291.95$ to 292.06$) \mathrm{K}, k=0.2133, r=0.9806$; $\nabla, T=(295.67$ to 295.77$) \mathrm{K}, k=0.2923, r=0.9865 ; \times, T=(299.06$ to 299.33) $\mathrm{K}, k=0.5753, r=0.9838 ; \diamond, T=(301.25$ to 301.31$) \mathrm{K}, k=$ $0.8880, r=0.9757$; - , fitting line; $k$, slope of the fitting line; $r$, linear correlation coefficient of the fitting line.

in temperature. The increasing rates of the phase equilibrium pressures increase with the increase in temperature. $\mathrm{NaCl}$ in solutions has an obvious inhibition effect on the formation of $\mathrm{CP}+$ methane hydrates. The phase equilibrium pressures of $\mathrm{CP}+$ methane hydrates in brine water were significantly higher than that in pure water. As can be seen from Figure $3 b$, the phase equilibrium pressures of $\mathrm{CP}+$ methane hydrates in brine water increase linearly with the increase in $\mathrm{NaCl}$ mass fraction (salinity) in solutions. The slopes of $P-100 \cdot w$ lines increase with the increase in temperature. The slopes of $P-100 \cdot w$ lines increase from 0.1113 to 0.8880 when the temperatures increase from ca. (286 to 301) K. This indicates that the effect of salinity on the phase equilibrium pressures of $\mathrm{CP}+$ methane hydrates increases at a high temperature. For the solutions with the $\mathrm{NaCl}$ mass fraction $w=0.035$ and 0.070 , the phase equilibrium pressures of $\mathrm{CP}+$ methane hydrate at $301.31 \mathrm{~K}$ are $(10.513$ and 11.888) $\mathrm{MPa}$, respectively. These pressures are lower than the seafloor pressure where common oceanic NGH formation occurs, (5 to 40) MPa.

Dissociation Enthalpy of Cyclopentane + Methane Hydrates. The formation/dissociation heat of $\mathrm{CP}+$ methane hydrates in hot brine takes an important role in our hydrate-

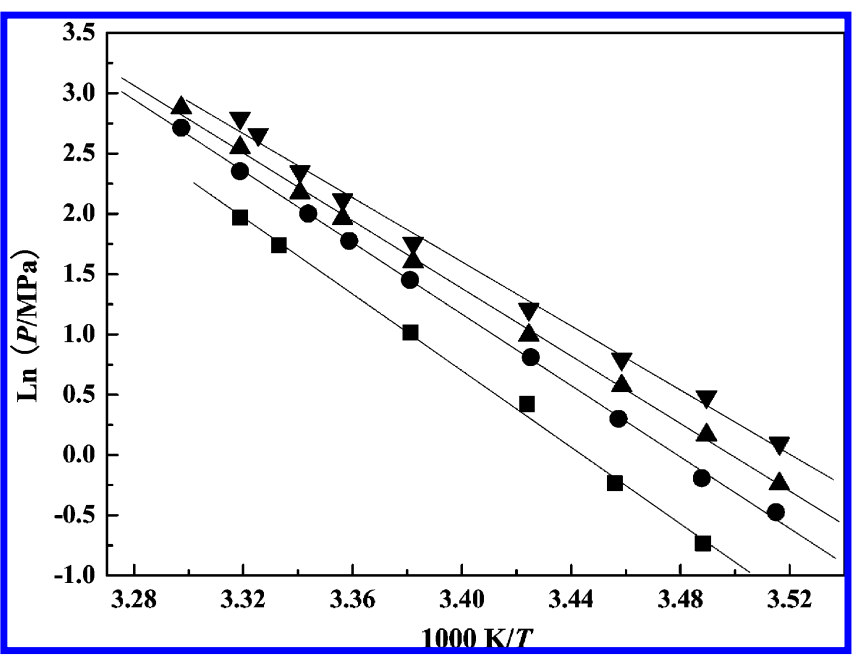

Figure 4. Semilogarithmic plots of the dissociation pressure versus the reciprocal temperature along the cyclopentane $\left(\mathrm{L}_{\mathrm{HC}}\right)-$ methane $(\mathrm{V})-$ brine water $\left(\mathrm{L}_{\mathrm{BW}}\right)$-hydrate $(\mathrm{H})$ coexistence lines. $\mathbf{\square}, w=0.000, k=-15877, r$ $=0.9987 ; \bullet, w=0.035, k=-14814, r=0.9996 ; \boldsymbol{\Delta}, w=0.070, k=$ $-14013, r=0.9994 ; \nabla, w=0.100, k=-13293, r=0.9973$; - , fitting line; $k$, slope of the fitting line; $r$, linear correlation coefficient of the fitting line.

based hot brine preparation, and these dissociation enthalpy data are required to develop production schemes. Dissociation enthalpies of gas hydrates are usually obtained by direct calorimetric measurement and indirect determination via the Clapeyron or Clausius-Clapeyron equation by differentiation of phase equilibrium pressure-temperature data. The formation and dissociation of $\mathrm{CP}+$ methane hydrates can be represented by the following equation

$$
\mathrm{CH}_{4}+x \mathrm{CP}+n \mathrm{H}_{2} \mathrm{O} \Leftrightarrow \mathrm{CH}_{4} \cdot x \mathrm{CP} \cdot n \mathrm{H}_{2} \mathrm{O}
$$

where $x$ and $n$ are the mole number of $\mathrm{CP}$ and $\mathrm{H}_{2} \mathrm{O}$ in hydrate crystalline, respectively.

To a first-order approximation, the hydrate dissociation enthalpy above $273.15 \mathrm{~K}$ can be determined from the univariant slope of the phase equilibrium line of $\ln (P / \mathrm{MPa})$ vs $T / \mathrm{K}$ using the Clausius-Clapeyron equation ${ }^{1}$

$$
\frac{d \ln P}{d(1 / T)}=\frac{-\Delta_{\mathrm{diss}} H_{\mathrm{m}\left(\mathrm{CH}_{4}\right)}}{Z R}
$$

where $P$ is the pressure; $T$ is the temperature; $Z$ is the compression factor of the guest gas $\left(\mathrm{CH}_{4}\right)$ at each equilibrium $P-T$ condition, and it can be calculated by the Soave-RedlichKwong (SRK) equation; $R$ is the universal gas constant $(R=$ $\left.8.31451 \mathrm{~J} \cdot \mathrm{mol}^{-1} \cdot \mathrm{K}^{-1}\right)$; and $\Delta_{\text {diss }} H_{\mathrm{m}\left(\mathrm{CH}_{4}\right)}$ is the molar dissociation enthalpy of $\mathrm{CP}+$ methane hydrates calculated by methane.

The $(P, T)$ data in Table 1 are plotted as $\ln (P / \mathrm{MPa})$ vs 1000 $T / \mathrm{K}$ in Figure 4 . As can be seen from Figure $4, \ln (P / \mathrm{MPa})$ vs $1000 \mathrm{~T} / \mathrm{K}$ exhibits a very good linear relation under all $\mathrm{NaCl}$ concentrations. The slopes $k$ in Figure 4 increase linearly with the increase in $\mathrm{NaCl}$ concentration in aqueous solution, which can be described by the linear equation of $k=25656.7 w-$ 15816.657 with a linear correlation coefficient $r=0.9976$.

The dissociation enthalpies of $\mathrm{CP}+$ methane hydrates in hot brine calculated by eq 2 are listed in Table 1 and displayed in Figure 5. As can be seen from Figure 5, $\Delta_{\text {diss }} H_{\mathrm{m}\left(\mathrm{CH}_{4}\right)}$ decreases with the increase in temperature and the increase in phase 


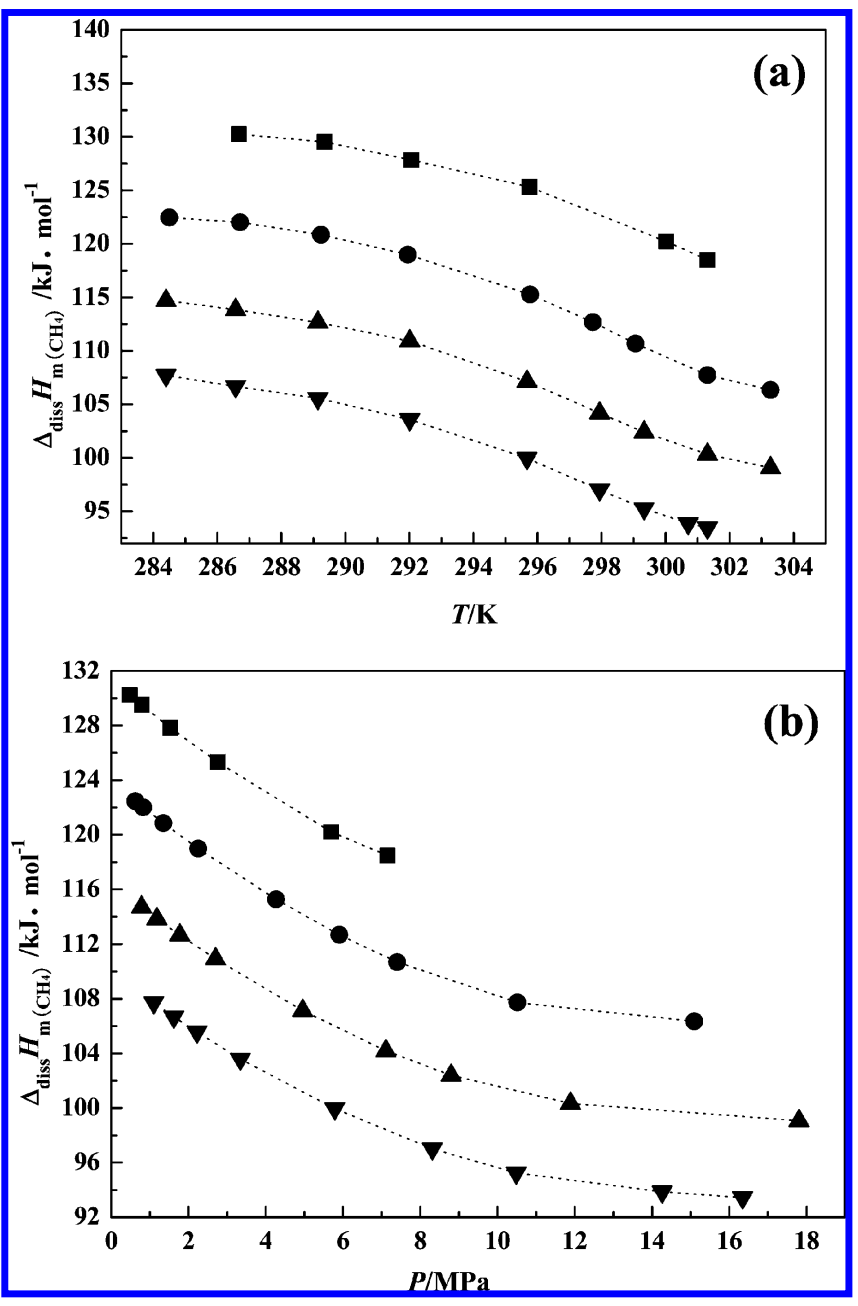

Figure 5. Dissociation enthalpy of cyclopentane + methane hydrates versus temperature (a) and pressure (b) in different $\mathrm{NaCl}$ solutions. $\mathbf{\square}, w=0.000$; $\boldsymbol{\ominus}, w=0.035 ; \boldsymbol{\Delta}, w=0.070 ; \boldsymbol{\nabla}, w=0.100 ; \Delta_{\mathrm{diss}} H_{\mathrm{m}\left(\mathrm{CH}_{4}\right)}$, dissociation enthalpy calculated by $\mathrm{CH}_{4}$.

equilibrium pressure under all salinity conditions. This was caused by the reduction of the compression factor $Z$ at conditions of high temperature and high pressure. The $\Delta_{\text {diss }} H_{\mathrm{m}\left(\mathrm{CH}_{4}\right)}$ decreases with the increase in $\mathrm{NaCl}$ concentration under a certain temperature because the phase equilibrium pressure of $\mathrm{CP}+$ methane hydrates increases with the increase in salinity and causes the decrease of $Z$. At the same time, the decrease of the absolute value of $k$ also causes a decrease in $\Delta_{\text {diss }} H_{\mathrm{m}\left(\mathrm{CH}_{4}\right)}$ with the increase in salinity. At $301 \mathrm{~K}$, the molar enthalpies of dissociation of $\mathrm{CP}+$ methane hydrates are $(118.49$, 107.73, 100.33 , and 93.44$) \mathrm{kJ} \cdot \mathrm{mol}^{-1}$ for aqueous solutions with the $\mathrm{NaCl}$ mass fraction of $w=0,0.035,0.070$, and 0.100 , respectively. The fractional occupancy of cages by methane increases slightly with the increase in methane fugacity. ${ }^{1}$ This may be one of the reasons for the decrease of $\Delta_{\mathrm{diss}} H_{\mathrm{m}\left(\mathrm{CH}_{4}\right)}$ at high temperature and high salinity conditions.

\section{Conclusions}

The phase equilibrium data of $\mathrm{CP}+$ methane hydrates were obtained in brine water with the $\mathrm{NaCl}$ mass fraction of $w=0$, $0.035,0.070$, and 0.100 , in the temperature range from $(284.4$ to 301.3 ) $\mathrm{K}$, using a visual high-pressure phase equilibrium apparatus. Liquid $\mathrm{CP}$ forms hydrate at a temperature region much higher than the quadruple point of pure $\mathrm{CP}$ hydrate when small molecule help gas presents. Methane partially occupies the small cages of structure II hydrate, which accelerates the nucleation and growth of $\mathrm{CP}+$ methane hydrates and increases its stability. $\mathrm{NaCl}$ in solutions has an obvious inhibition effect on the formation of $\mathrm{CP}+$ methane hydrate. The phase equilibrium pressure of $\mathrm{CP}+$ methane hydrates increases with the increase in temperature, and it increases linearly with the increase in $\mathrm{NaCl}$ concentration. The higher the temperature, the more remarkable effect the temperature and salinity have on the phase equilibrium pressure. The dissociation enthalpies of $\mathrm{CP}+$ methane hydrates in hot brine water were determined via Clausius-Clapeyron equation based on the measured phase equilibrium data. The dissociation enthalpy decreases with the increase in temperature and the increase in $\mathrm{NaCl}$ concentration because the increase in temperature and the salinity of solutions increase the phase equilibrium pressure, which caused the decrease of $Z$ and the increase of the fractional occupancy of cages by methane.

\section{Literature Cited}

(1) Sloan, E. D.; Koh, C. A. Clathrate hvdrates of natural gases, 3rd ed.; Taylor \& Francis CRC Press: New York, 2007.

(2) Makogon, Y. F.; Holditch, S. A. Natural gas hydrates-A potential energy source for the 21st century. J. Pet. Sci. Eng. 2007, 56, 14-31.

(3) Selim, M. S.; Sloan, E. D. Heat and mass transfer during the dissociation of hydrates in porous media. AIChE J. 1989, 35 (6), 10491052.

(4) Chuang, J.; Ahmadi, G.; Smith, D. H. Natural gas production from hydrate decomposition by depressurization. Chem. Eng. Sci. 2001, 56, $5801-5814$

(5) Sung, W.; Lee, H.; Lee, H.; Lee, C. Numerical study for production performances of a methane hydrate reservoir stimulated by inhibitor injection. Energy Sources 2002, 24, 499-512.

(6) Lee, H.; Seo, Y.; Seo, Y. T.; Moudrakovski, I. L.; Ripmeester, J. A. Recovering methane from solid methane hydrate with carbon dioxide. Angew. Chem. Int. Ed. 2003, 42, 5048-5051.

(7) Moridis, G. J. Numerical studies of gas production from methane hydrates. SPE J. 2003, 8, 359-370.

(8) Kamath, V. A.; Godbole, S. P. Evaluation of hot-brine stimulation technique for gas production from natural hydrates. J. Pet. Technol. 1987, 39, 1379-1388.

(9) Chen, Z. Y.; Li, X. S.; Yan, K. F.; Li, G. A method and device for exploiting natural gas hydrates. CN101016841A, 2007.

(10) Max, M. D.; Holman, S.; Osegovic, J.; Tatro, S.; Hill, J. Use of gas hydrate for desalination and water purification. MDS final report to DARPA; Jan. 2004; p 147

(11) Fan, S. S.; Liang, D. Q.; Guo, K. H. Hydrate equilibrium conditions for cyclopentane and a quaternary cyclopentane-rich mixture. J. Chem. Eng. Data 2001, 46, 930-932.

(12) Østergaard, K. K.; Tohidi, B.; Burgass, R. W.; Danesh, A.; Todd, A. C. Hydrate equilibrium data of multicomponent systems in the presence of structure-II and structure- $\mathrm{H}$ heavy hydrate formers. J. Chem. Eng. Data 2001, 46, 703-708.

(13) Ripmeester, J. A.; Ratcliffe, C. I.; McLaurin, G. E. The role of heavier hydrocarbons in hydrate formation. AIChE Spring Meeting, Session 44. Hydrates in the Gas Industry, 1991.

(14) Sun, Z. G.; Fan, S. S.; Guo, K. H.; Shi, L.; Guo, Y. K.; Wang, R. Z. Gas hydrate phase equilibrium data of cyclohexane and cyclopentane. J. Chem. Eng. Data 2002, 47, 313-315.

(15) Mohammadi, A. H.; Richon, D. Phase equilibria of clathrate hydrates of cyclopentane + hydrogen sulfide and cyclopentane + methane. Ind. Eng. Chem. Res. 2009, 48, 9045-9048.

(16) Tohidi, B.; Danesh, A.; Todd, A. C.; Burgass, R. W.; Østergaard, K. K. Equilibrium data and thermodynamic modelling of cyclopentane and neopentane hydrates. Fluid Phase Equilib. 1997, 138, 241-250.

(17) Zhang, J. S.; Lee, J. W. Equilibrium of hydrogen + cyclopentane and carbon dioxide + cyclopentane binary hydrates. J. Chem. Eng. Data 2009, 54 (2), 659-661.

(18) Takeya, S.; Ohmura, R. Phase equilibrium for structure II hydrates formed with krypton co-existing with cyclopentane, cyclopentene, or tetrahydropyran. J. Chem. Eng. Data 2006, 51, 1800-1883.

(19) Imai, S.; Okutani, K.; Ohmura, R.; Mori, Y. H. Phase equilibrium for clathrate hydrates formed with difluoromethane + either cyclopentane or tetra-n-butylammonium bromide. J. Chem. Eng. Data 2005, 50, $1783-1786$

(20) Taylor, C. J.; Miller, K. T.; Koh, C. A.; Sloan, E. D. Macroscopic investigation of hydrate film growth at the hydrocarbon/water Interface. Chem. Eng. Sci. 2007, 62, 6524-6533. 
(21) Sakemoto, R.; Sakamoto, H.; Shiraiwa, K.; Ohmura, R.; Uchida, T. Clathrate hydrate crystal growth at the seawater/hydrophobic-guestliquid interface. Cryst. Growth Des. 2010, 10 (3), 1296-1300.

(22) Whitman, C. A.; Mysyk, R.; White, M. A. Investigation of factors affecting crystallization of cyclopentane clathrate hydrate. J. Chem. Phvs. 2008, 129, 174502.

(23) Zhang, Y. F.; Debenedetti, P. G.; Prud'homme, R. K.; Pethica, B. A Differential scanning calorimetry studies of clathrate hydrate formation. J. Phvs. Chem. B 2004, 108, 16717-16722.

(24) Bishnoi, P. R.; Dhloabhai, P. D. Experimental study on propane hydrate equilibrium condition in aqueous electrolyte solutions. Fluid Phase Equilib. 1993, 83, 455-462.
(25) Chen, G. J.; Guo, T. M. A new approach to gas hydrate modeling. Chem. Eng. J. 1998, 71, 145-151.

Received for review May 30, 2010. Accepted August 9, 2010. This work was supported by grants from the National Natural Science Foundation of China (Nos. 50874098, U0733003, 20773133), Guangdong Province Natural Science Foundation (No. 07301638), Knowledge Innovation Project of Chinese Academy of Sciences (No. KGCX-YW-3X6), and Science \& Technology Program of Guangdong Province (2009B050600006), which are gratefully acknowledged.

JE100597E 